\title{
Numerical and Experimental Investigations of Leak Detection in Single Branched Pipeline System
}

\author{
$\left\{\text { H. Abozaid }{ }^{1} \text {, A. Abou El-Azm Aly }{ }^{2} \text {, A. H. Lotfy }{ }^{3}\right\}^{4}$
}

\begin{abstract}
Leakage in pipeline networks leads to excessive economical losses as well as poses environmental hazards. The leakage detection has been addressed by many researchers throughout the last few decades by using various techniques. Nowadays, these techniques have been modified and enhance to be faster with the advanced technology in sensors and computers, so this area of research has to be revisited. In the present study, the occurrence of leakage in a single branched pipeline system has been investigated theoretically and verified experimentally. The theoretical model of a proposed pipeline system has been modeled by applying the governing fluid flow equations using MATLAB capabilities. The pipeline system in the investigation has been supplied with water from a constant head tank. The pipeline system used in the theoretical investigation, of leakage detection, has been realized (established) practically in the Fluid Mechanics Laboratory of the Mechanical Power Department in the Military Technical College. The fluid flow parameters such as: pressure in the pipeline, volume flowrate, leak location, and leak flowrate have been measured in both conditions of pipeline flow; without and with leakage occurrence. To investigate the effect of leakage occurrence on the pipeline parameters (pressure and flowrate) at pipeline entrance section, both the leak locations and the leak opening diameters have been varied in the theoretical model and experimentally. The ranges of leak location, $x / L$, is from 0.05 to 0.95 and the ranges of leak diameter, $d / D$, is from 0.2 to 0.7 . The results of the theoretical investigation and the experimental measurements have been in good agreement. It has been found that, the fluid flow parameters, pressure and flowrate, at entrance of the pipeline system are greatly affected by the leak location and its opening size. So the detection of leak location and its flowrate could be predicted, from the information of changes in the pipeline pressure and flowrate at the entrance of the pipeline system after leakage occurrence.
\end{abstract}

\section{Introduction}

Leakage detection has been received attention from researchers in the last decades. With the advances in technology of sensors, computers, the leakage detection techniques have been modified and enhanced to be faster, precise, accurate, and field adapted. Among the recent researches, Zhang [10] classified the leak detection methods into three groups; first group is simple physical inspection method; by using some experienced personnel or trained dogs to detect and locate the leak by visual inspection, odor, or sound. Second group is hardware based method; by using different hardware devices to assist the detection and location of the leak,

\footnotetext{
hossam.abozaid@yahoo.com

aboazm2005@yahoo.com

ahlotfy288@yahoo.com

Egyptian Armed Forces, Egypt.
} 
typical devices could be used including acoustic sensors, gas detectors, negative pressure detectors, and infrared thermograph. Third group is software-based method; where various computer software packages could be used to detect the leak in pipelines, the complexity and reliability of these packages vary significantly. Examples of these methods are; the detection of the flow/pressure changes; the mass/volume balance; the dynamic model-based system; and the pressure point analysis. The block scheme shown in Figure 1 simplifies the classification of the leak detection methods as addressed in reference [10], for each method the referred references have been indicated. The detailed description of the above classified methods of leak detection could be found in reference [9] under preparation for discussion and the process of publication.

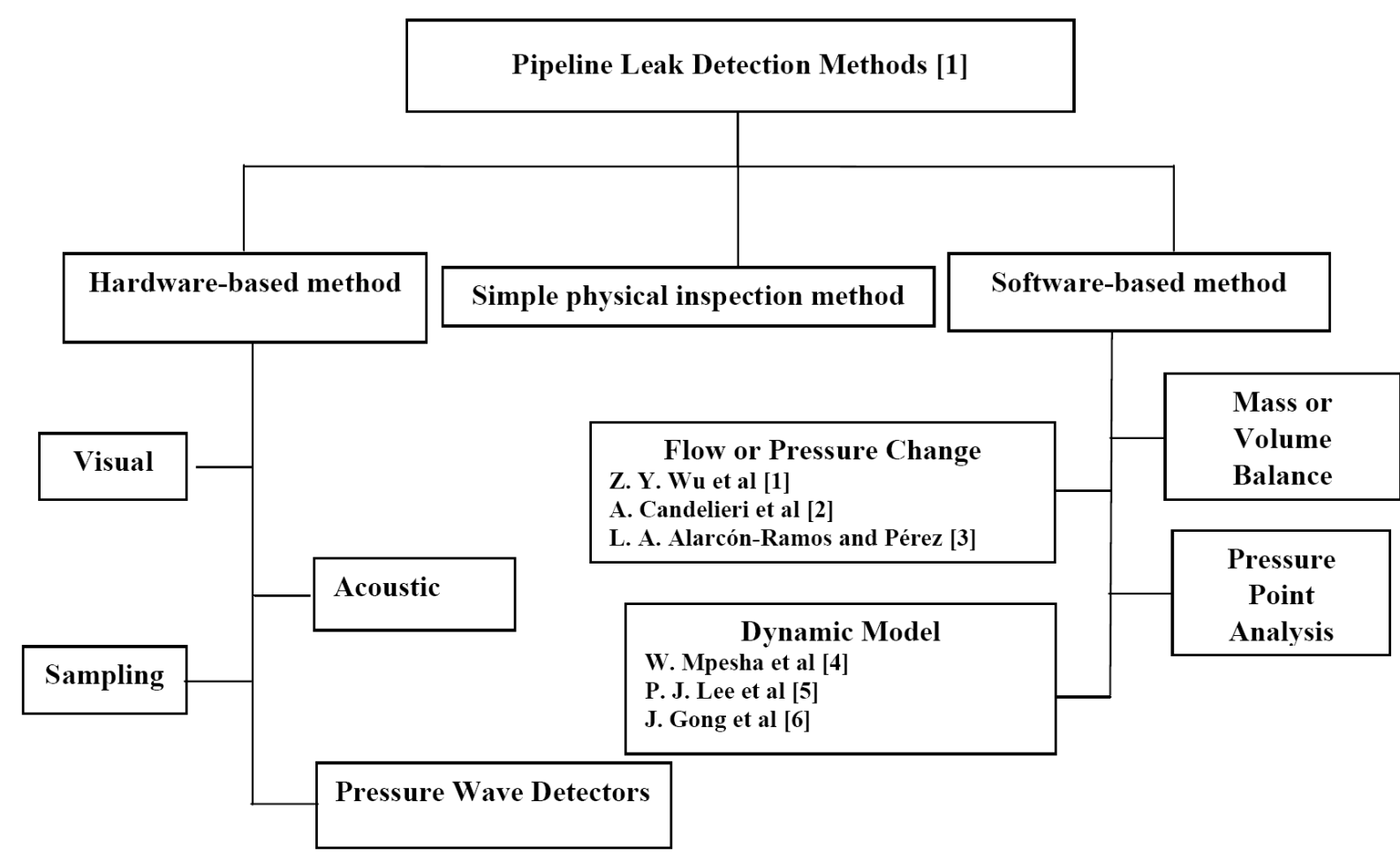

Fig. 1. Classification of the leak detection methods

\section{Theoretical Investigation of Leakage Detection in Pipeline System}

A computer program has been built to solve the governing equations of a proposed pipeline system. The pipeline characteristics (pressure head and flowrate) have been investigated for the pipeline without leakage then the code has been modified to study the effect of leakage occurrence on the pipeline parameters (pressure and flowrate) at pipeline entrance section. The effect of leakage opening size (branched exit) and its location on the pipeline flow parameters (pressure and flowrate) at pipeline entrance section, have been investigated, in order to study the effect of leakage locations and their opening sizes.

\subsection{Proposed Pipeline System}

The opened loop of a single pipeline system, shown in Figure 2, is supplied with water from a constant head tank filled up to an elevation of $16.3 \mathrm{~m}$ above the location of the test section (entrance of the pipeline system). The pipeline system consists of the following elements; polypropylene pipes of diameter $\mathrm{D}=25.4 \mathrm{~mm}$ with total length of 53 meters; 30 elbows, and a ball-valve for controlling the water flowrate. To simulate the leakage openings, some branched connections, shown in Figure 2, of various exit diameters, d, have been attached at some predetermined locations, $\mathrm{x}$, along the pipeline system to simulate the leakage at this location. The 
mathematical model has been applied from the entrance section of the pipeline system downstream to its exit section. The constant head tank is supplied with water from a pumping system connecting the lower tank (in the fluid mechanics laboratory) to the upper tank (at the building roof) and the over flow from the upper tank returns back to the lower one through a pipe of one-inch diameter provided with transparent hose at its exit to visualize the overflow in the laboratory.

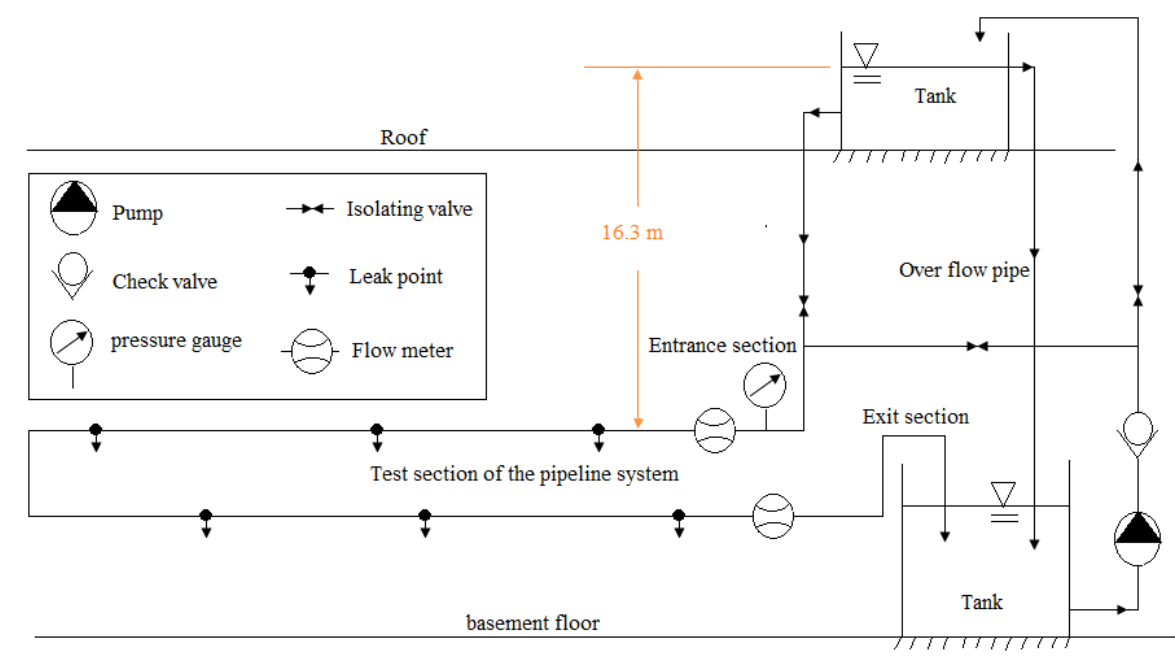

Fig 2. Arrangement of the proposed single pipeline system.

\subsection{Mathematical Model of the Pipeline Without Leakage}

To investigate the single pipeline system flow parameters (pressure and flowrate) at pipeline entrance section, with leakage occurrence, it is important to determine the characteristics of this pipeline system without leakage occurrence for comparison of the two conditions. A mathematical model has been constructed to simulate the pipeline system without leakage as follows:

\subsubsection{Energy equation}

The energy equation has been applied between the free-surface of the constant head storage tank (subscripted by "o") and the pipeline exit at the lower water tank (subscripted by "exit"):

$$
\frac{\mathrm{p}_{0}}{\rho \mathrm{g}}+\frac{\mathrm{v}_{0}^{2}}{2 \mathrm{~g}}+\mathrm{z}_{0}=\frac{\mathrm{p}_{\text {exit }}}{\rho \mathrm{g}}+\frac{\mathrm{v}_{\text {exit }}^{2}}{2 \mathrm{~g}}+\mathrm{z}_{\text {exit }}+\left(\mathrm{f} \frac{\mathrm{L}}{\mathrm{D}}+\sum \mathrm{k}_{\mathrm{l}_{0 \rightarrow \text { exit }}}\right) \frac{\mathrm{v}_{\text {exit }}^{2}}{2 \mathrm{~g}}
$$

After applying the flow boundary conditions, it takes the following form:

$$
\begin{gathered}
\mathrm{z}_{0}=\frac{\mathrm{v}_{\text {exit }}^{2}}{2 \mathrm{~g}}+\left(\mathrm{f} \frac{\mathrm{L}}{\mathrm{D}}+\sum \mathrm{k}_{\mathrm{l}_{0 \rightarrow \text { exit }}}\right) \frac{\mathrm{v}_{\text {exit }}^{2}}{2 \mathrm{~g}} \\
\mathrm{v}_{\text {exit }}=\sqrt{\frac{2 \mathrm{gz}_{0}}{\left(1+\mathrm{f} \frac{\mathrm{L}}{\mathrm{D}}+\sum \mathrm{k}_{\mathrm{l}_{0 \rightarrow \text { exit }}}\right)}}
\end{gathered}
$$

2.2.2 Cole-Brook-White empirical formula

$$
\frac{1}{\sqrt{f}}=1.14-2 \log _{10}\left(\frac{\varepsilon}{D}+\frac{9.35}{\operatorname{Re} \sqrt{f}}\right)
$$

The energy equation, Equation (3), has two unknowns; the pipe friction factor, $f$; and the pipeline exit velocity, $v_{\text {exit }}$, so the Cole-Brook-White empirical formula, Equation (4), has been used with Equation (3) to determine the pipe friction factor, $\mathrm{f}$, and then the pipeline exit velocity, $v_{\text {exit }}$. 
All local losses in the single pipeline system from the constant head tank exit section (entrance of the pipeline system) downstream to the pipeline exit into the lower tank $\left(\sum \mathrm{k}_{\mathrm{l}_{0 \rightarrow \text { exit }}}\right)$ are selected from the published tables and charts in reference [1].

\subsection{Mathematical Model of the Pipeline with Leakage}

In order to investigate the flow parameters (pressure and flowrate) at pipeline entrance section, of the single pipeline system with leakage occurrence, the mathematical model has been modified, as shown in Figure 3, to simulate the pipeline system with leakage occurrence from a branched exit. The mathematical equations describing the flow in the pipeline system with leakage occurrence are addressed as follows.

\subsubsection{Mass conservation equation}

For steady incompressible fluid flow, the continuity equation takes the following form:

$$
\mathrm{Q}_{1}=\mathrm{Q}_{2}+\mathrm{Q}_{3}
$$

\subsubsection{Energy conservation equation}

The energy equation governing the steady incompressible viscous fluid flow between the section (1) and the section (2) downstream, takes the following form:

$$
\frac{\mathrm{p}_{1}}{\rho g}+\frac{\overline{\mathrm{v}}_{1}^{2}}{2 g}+\mathrm{z}_{1}=\frac{\mathrm{p}_{2}}{\rho g}+\frac{\overline{\mathrm{v}}_{2}^{2}}{2 g}+\mathrm{z}_{2}+\sum h_{l 1 \rightarrow 2}
$$

where, $\sum h_{l 1 \rightarrow 2}=\left(\sum K_{1 \rightarrow 2}+\mathrm{f} \frac{L_{1 \rightarrow 2}}{D}\right) \frac{\overline{\mathrm{v}}_{1}^{2}}{2 g}$ are the sum of local and friction losses in the pipeline section $(1-2)$. The energy equation, Equation (6), has been applied at the three sections simultaneously as follows; between sections (a) and (b); between sections (b) and (c) and between sections (b) and (e).

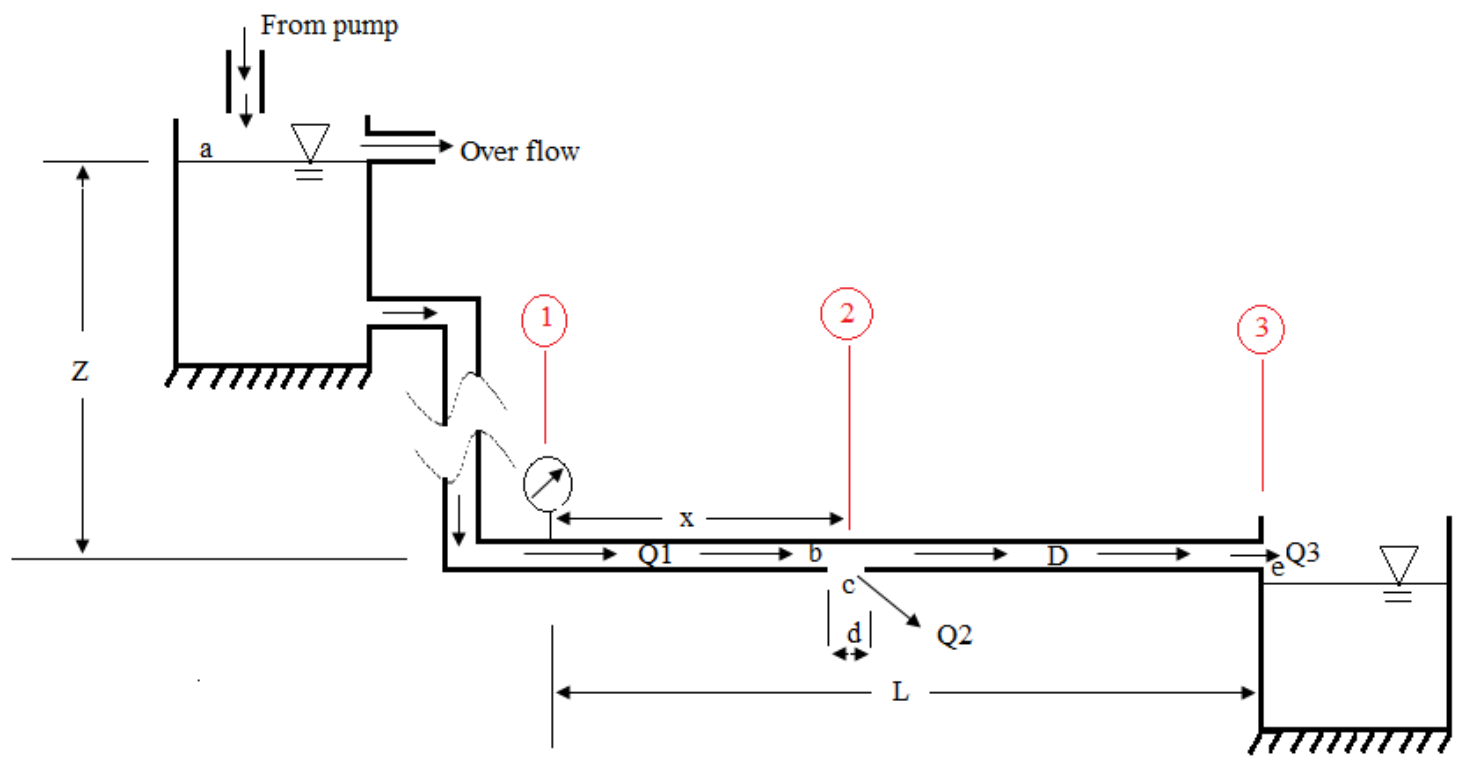

Fig. 3. Notations of the pipeline with a branched exit, $d / D$, at the leakage position, $x / L$.

2.3.3 Energy equation between sections (a) and (b)

$$
\frac{\mathrm{p}_{\mathrm{a}}}{\rho g}+\frac{\overline{\mathrm{v}}_{\mathrm{a}}^{2}}{2 g}+\mathrm{z}_{\mathrm{a}}=\frac{\mathrm{p}_{\mathrm{b}}}{\rho g}+\frac{\overline{\mathrm{v}}_{\mathrm{b}}^{2}}{2 g}+\mathrm{z}_{\mathrm{b}}+\sum h_{l a \rightarrow b}
$$

Given: $\mathrm{p}_{\mathrm{a}}=0, \overline{\mathrm{v}}_{\mathrm{a}}=0, \frac{\mathrm{p}_{\mathrm{b}}}{\rho g}=h, \overline{\mathrm{v}}_{\mathrm{b}}=\frac{\mathrm{Q}_{1}}{\mathrm{~A}}, L_{a \rightarrow b}=x$ 
After substitution in the above energy equation it takes the following form:

$$
z_{a}=h+\left(1+\sum K_{a \rightarrow b}+f_{1} \frac{x}{D}\right) \frac{Q_{1}^{2}}{2 g A^{2}}
$$

2.3.4 Energy equation between sections (b) and (c):

$$
\frac{\mathrm{p}_{\mathrm{b}}}{\rho g}+\frac{\overline{\mathrm{v}}_{\mathrm{b}}^{2}}{2 g}+\mathrm{z}_{\mathrm{b}}=\frac{\mathrm{p}_{\mathrm{c}}}{\rho g}+\frac{\overline{\mathrm{v}}_{\mathrm{c}}^{2}}{2 g}+\mathrm{z}_{\mathrm{c}}+\sum h_{l b \rightarrow c}
$$

After substitution with boundary conditions, it reduces to the following form:

$$
\frac{\mathrm{p}_{\mathrm{b}}}{\rho g}+\frac{\overline{\mathrm{v}}_{\mathrm{b}}^{2}}{2 g}=\frac{\overline{\mathrm{v}}_{\mathrm{c}}^{2}}{2 g}+\sum h_{l b \rightarrow c}
$$

where

$$
\sum h_{l b \rightarrow c}=K_{b \rightarrow c} \frac{\overline{\mathbf{v}}_{\mathbf{b}}^{2}}{2 g}
$$

The local loss coefficient $K_{b \rightarrow c}$ depends on the ratio of d/D and that of $Q_{2} / Q_{1}$, according to the published data in reference [1], then the energy equation applied at pipeline sections $\mathrm{b}$ and $\mathrm{c}$, takes the following form:

$$
\frac{\mathrm{p}_{\mathrm{b}}}{\rho g}+\frac{\overline{\mathrm{v}}_{\mathrm{b}}^{2}}{2 g}=\frac{\overline{\mathrm{v}}_{\mathrm{c}}^{2}}{2 g}+K_{b \rightarrow c} \frac{\overline{\mathrm{v}}_{\mathrm{b}}^{2}}{2 g}
$$

Rearranging, it takes the following form:

$$
h+\frac{\mathrm{Q}_{1}^{2}}{2 g A^{2}}=\frac{\mathrm{Q}_{2}^{2}}{2 g a^{2}}+K_{b \rightarrow c} \frac{\mathrm{Q}_{1}^{2}}{2 g A^{2}}
$$

2.3.5 Energy equation between sections (b) and (e):

$$
\frac{\mathrm{p}_{\mathrm{b}}}{\rho g}+\frac{\overline{\mathrm{v}}_{\mathrm{b}}^{2}}{2 g}+\mathrm{z}_{\mathrm{b}}=\frac{\mathrm{p}_{\mathrm{e}}}{\rho g}+\frac{\overline{\mathrm{v}}_{\mathrm{e}}^{2}}{2 g}+\mathrm{z}_{\mathrm{e}}+\sum h_{l b \rightarrow e}
$$

After substitution with boundary conditions, it reduces to the following form:

$$
h+\frac{\overline{\mathrm{v}}_{\mathrm{b}}^{2}}{2 g}=\frac{\overline{\mathrm{v}}_{\mathrm{e}}^{2}}{2 g}+\sum h_{l b \rightarrow e}
$$

The total head losses $\sum h_{l b \rightarrow e}$ consist of three terms as given in reference [10]:

$$
\sum h_{l b \rightarrow e}=\frac{\left(\overline{\mathrm{v}}_{\mathrm{b}}-\overline{\mathrm{v}}_{\mathrm{e}}\right)^{2}}{2 g}+K_{\text {exit }} \frac{\overline{\mathrm{v}}_{\mathrm{e}}^{2}}{2 g}+f_{3} \frac{(L-x)}{D} \frac{\overline{\mathrm{v}}_{\mathrm{e}}^{2}}{2 g}
$$

where, $\overline{\mathrm{v}}_{\mathrm{e}}=\frac{\mathrm{Q}_{3}}{\mathrm{~A}}$

Then, rearranging the energy equation, it takes the following form:

$$
h+\frac{\overline{\mathrm{v}}_{\mathrm{b}}^{2}}{2 g}=\frac{\overline{\mathrm{v}}_{\mathrm{e}}^{2}}{2 g}+\frac{\left(\overline{\mathrm{v}}_{\mathrm{b}}-\overline{\mathrm{v}}_{\mathrm{e}}\right)^{2}}{2 g}+K_{\text {exit }} \frac{\overline{\mathrm{v}}_{\mathrm{e}}^{2}}{2 g}+f_{3} \frac{(L-x)}{D} \frac{\overline{\mathrm{v}}_{\mathrm{e}}^{2}}{2 g}
$$

and finally as follows:

$$
h+\frac{\mathrm{Q}_{1}^{2}}{2 g A^{2}}=\frac{\left(\frac{Q_{1}}{A}-\frac{Q_{3}}{A}\right)^{2}}{2 g}+\left(1+K_{\text {exit }}+f_{3} \frac{(L-x)}{D}\right) \frac{\mathrm{Q}_{3}^{2}}{2 g A^{2}}
$$

\subsubsection{Empirical formula of Cole-Brook-White}

The Darcy-Weisbach method has been used to calculate the friction losses in the pipeline. By applying Colebrook-White empirical formula along the pipeline section $(a-b)$ it takes the following form: 


$$
\frac{1}{\sqrt{f_{1}}}=1.14-2 \log _{10}\left(\frac{\varepsilon}{\mathrm{D}}+\frac{9.35}{R e_{1} \sqrt{f_{1}}}\right)
$$

Then by applying the Colebrook-White empirical formula along the pipeline section (b - e), it takes the following form:

$$
\frac{1}{\sqrt{f_{3}}}=1.14-2 \log _{10}\left(\frac{\varepsilon}{\mathrm{D}}+\frac{9.35}{R e_{3} \sqrt{f_{3}}}\right)
$$

\subsection{Results of Theoretical Investigation}

The governing equations that simulate the single pipeline system with branched exit at leakage position have been solved for various cases of leakage positions, $x$, and leakage exit diameters, d. The effect of leakage occurrence at various locations, $x / L$, from 0.05 to 0.95 , with various diameter ratios, d/D, from 0.2 to 0.7 have been investigated. The effect of leakage position, $x / L$, on the pressure head ratio, $H / H_{\text {no-leak }}$, at the pipeline entrance section for various opening ratios, $d / D$, have been plotted and presented in Figure 4.

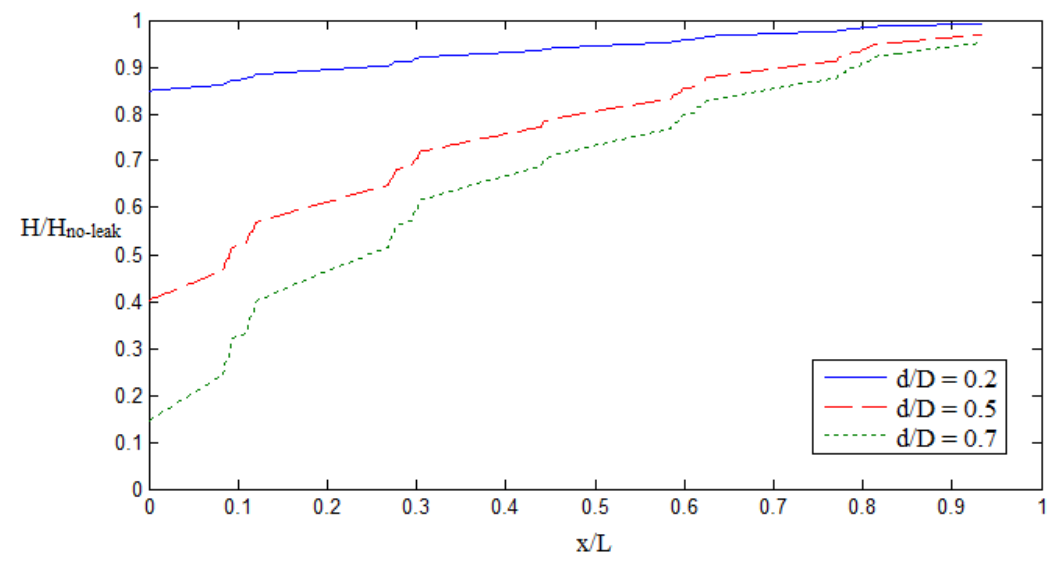

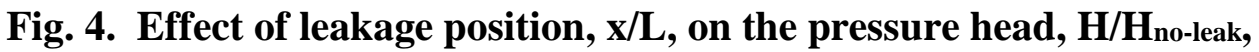
at entrance section of pipeline for various leakage openings, $d / D$.

It is noticed that the pressure head, $H / H_{n o-l e a k}$, at the pipeline entrance section decreases with the increase of the leakage opening, $d / D$, and at fixed leakage opening, $d / D$, the pressure head, $H / H_{n o-l e a k}$, at the pipeline entrance section increases with the increase of leakage location, $\mathrm{x} / \mathrm{L}$, downstream the pipeline entrance. These observations, may lead to the possibility of determination of the leakage location and the estimation of its opening size, from the knowledge of the measured pressure head, $H$, at the pipeline entrance section, $x / L=0$.

The mathematical model of the pipeline system with leakage has been used to calculate the flowrates (upstream the leakage opening, $\mathrm{Q}_{1}$, at the exit of leakage opening, $\mathrm{Q}_{2}$, and downstream the leakage opening, $\mathrm{Q}_{3}$ ) in the pipeline system where the leakage position varies from $\mathrm{x} / \mathrm{L}=0.25$ to 0.86 and where leakage exit diameter ratio varies from $\mathrm{d} / \mathrm{D}=0.2$ to 0.7 . as an illustrated example Figure 5. present the effect of leakage position on the behavior of the three discharges $\left(\mathrm{Q}_{1} / \mathrm{Q}_{\text {no-leak }}, \mathrm{Q}_{2} / \mathrm{Q}_{\text {no-leak }}, \mathrm{Q}_{3} / \mathrm{Q}_{\text {no-leak }}\right)$ downstream the pipeline system at various locations, $\boldsymbol{x} / \boldsymbol{L}$ in case of flow with leakage occurrence at exit diameter ratios $(\mathrm{d} / \mathrm{D}=0.5)$, as an example, another results for other leakage openings could be found in reference [9].

The flowrate at the entrance of pipeline system, $\mathrm{Q}_{1}$, upstream the leakage location, $\mathrm{x} / \mathrm{L}$, at all leakage openings, $d / D$, is greater than that of the pipeline flow without leakage $\left(\mathrm{Q}_{1 /} \mathrm{Q}_{\text {no-leak }}>\right.$ 1). That may be attributed to the increase in the flowrate $Q_{1}$ which causes the increase in the friction losses in the pipeline section upstream the leakage location, $x / L$; consequently it causes decrease in the pressure head at the entrance section $\left(\mathrm{H} / \mathrm{H}_{\text {no-leak }}<1\right)$. 
The effect of leakage location, $\mathrm{x} / \mathrm{L}$, on the upstream flowrate, $\mathrm{Q}_{1} / \mathrm{Q}_{\text {no-leakage, at various leakage }}$ openings, $d / D$, have been plotted in Figure 6. It is noticed that the increase in the upstream flowrate, $\mathrm{Q}_{1} / \mathrm{Q}_{\text {no-leak}}$, at the pipeline entrance section $(\mathrm{x} / \mathrm{L}=0)$ is directly proportional to the leakage opening, $d / D$, and at fixed leakage opening, $d / D$, the upstream flowrate, $\mathrm{Q}_{1} / \mathrm{Q}_{\text {no-leak}}$, at the entrance $(\mathrm{x} / \mathrm{L}=0)$ of the pipeline is greater than 1 and becomes close to 1.0 as the leakage location, $\mathrm{x} / \mathrm{L}$, moves downstream the entrance of the pipeline system.

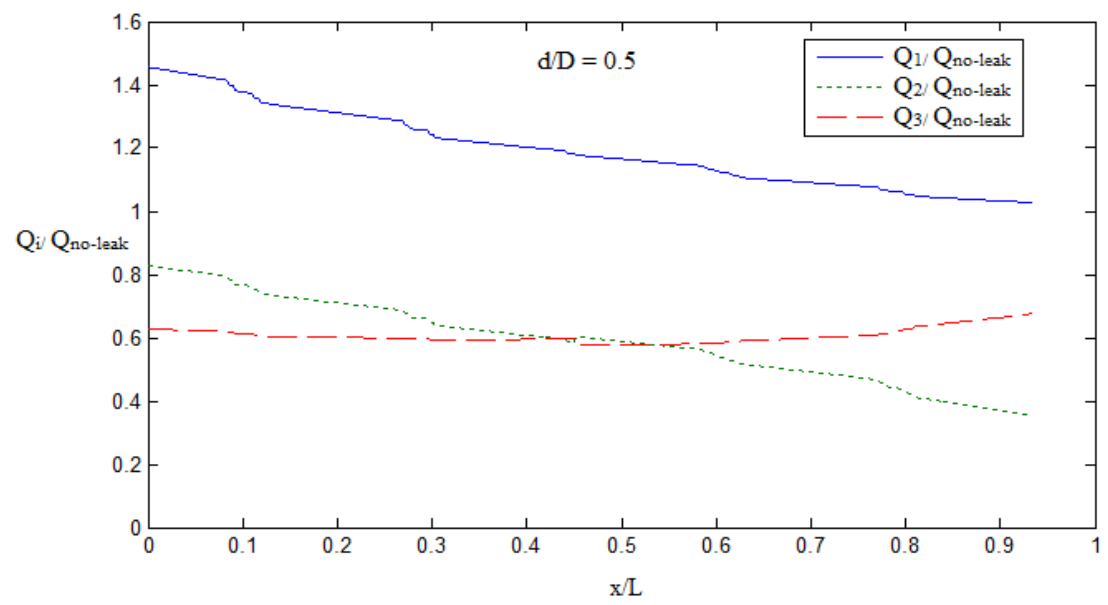

Fig. 5. Flowrates (upstream $Q_{1}$, at leakage exit $Q_{2}$, and downstream $Q_{3}$ ) versus leakage locations, $x / L$, along the pipeline at $d / D=0.5$.

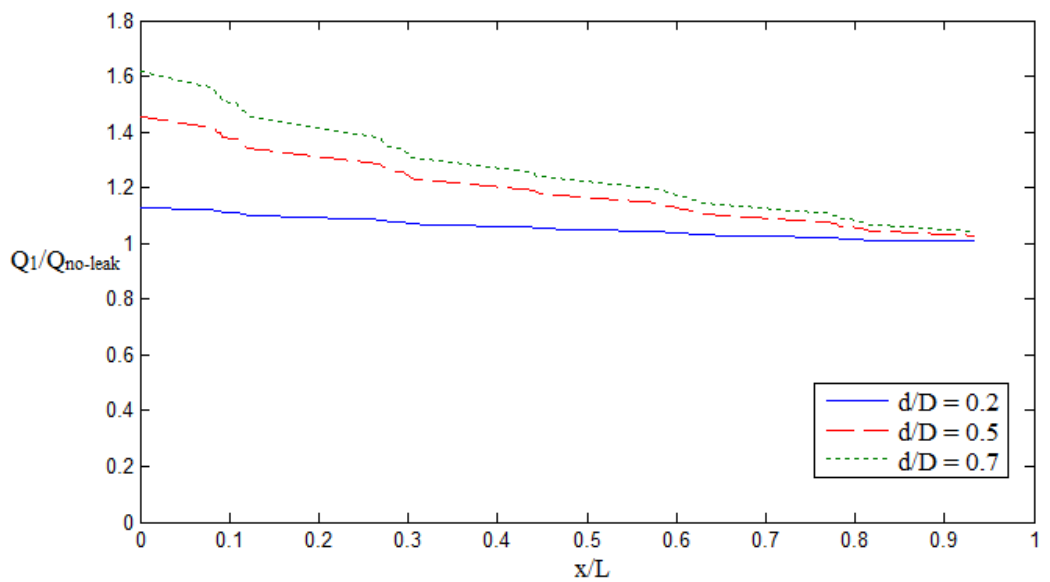

Fig. 6. Effect of leakage location $x / L$ on the upstream flowrate, $Q_{1}$, at the pipeline entrance section for various $d / D$.

These observations may lead to the possibility of determination of the leakage location and the estimation of the opening size from the measurement of the upstream flowrate, $Q_{1}$, at the pipeline entrance section $(x / L=0)$.

\section{Experimental Investigations}

The proposed layout of the test rig has been realized and established in the Fluid Mechanics Laboratory of Mechanical Power and Energy Department to verify the mathematical model of the theoretical investigation. Flow rate meters and pressure transducers have been calibrated and installed in the pipeline system to measure the pipeline characteristics without leakage occurrence and the flow parameters (pressure and flowrate) at pipeline entrance section, with leakage occurrence. 


\subsection{Description of the Test Rig}

The test rig, that shown in Figure 2, has been realized practically as shown in Figure 7.(a) which consists of a single pipeline system made of a polypropylene material in the form of a closed loop, connecting a water storage tank (constant head tank) at the roof of the building, with a lower metallic storage tank in the laboratory of fluid mechanics where the test section has been established. The selected centrifugal pump has been used to transport the water from the lower metallic storage tank, at the laboratory floor, to the constant head fiber tank, at the roof of the building. The overflow water returns back to the lower storage tank through a separate pipe.

The elevation of the free surface of the constant head tank is $16.3 \mathrm{~m}$. above the entrance of the test section of the single pipeline system. The single pipeline system been provided with special connections as shown in Figure 8, which simulate the leakage exit openings (from which the water leaks outside the pipeline system) with various leakage areas and fitted at some selected locations. The pipeline system has been assembled from polypropylene pipes of $25.4 \mathrm{~mm}$ diameter. The pipeline system consists of the following elements; total pipeline length of 53.0 $\mathrm{m}$. measured from the exit of the constant head tank to the end of the pipeline (exit to the lower metallic tank), 30 elbows, and 3 ball-valves for controlling the water flowrate, beside the special connections.

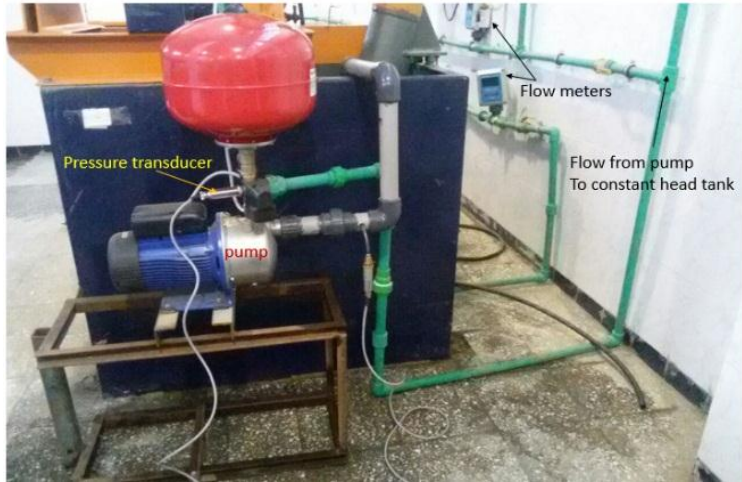

(a)

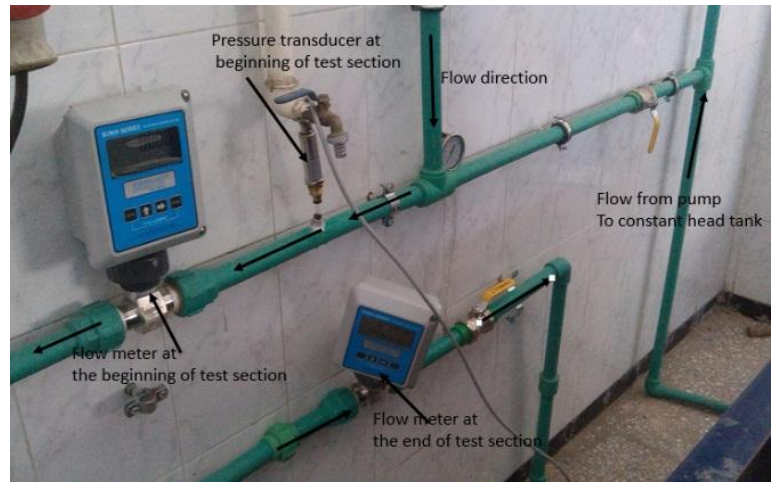

(b)

Fig. 7. (a)Test rig of the pipeline system, (b) Flowmeters and pressure transducer in fluid mechanics laboratory of the mechanical power and energy department.

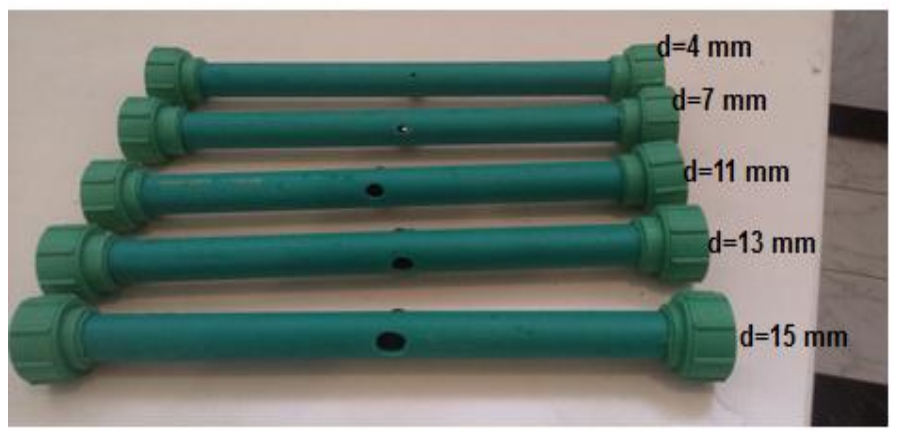

Fig. 8. Special connections simulate the leakage openings with various exit areas, $d / D$

Two flowrate meters and pressure transducer, shown in Figure 7.(b), have been installed at the entrance of the test section to measure the flowrate and the corresponding static pressure head at the entrance section of pipeline system with leakage occurrence. Another pressure transducer is installed at the exit section of the pipeline system to determine the pipeline characteristics without leakage occurrence. 


\subsection{Experimental Setup}

The selected pump is of centrifugal radial flow type "LOWARA" model "BG11". All measuring instruments, flowmeters and pressure transducers, have been calibrated before usage in the experimental measurements.

\subsection{Pipeline Characteristics without Leakage Occurrence}

The flowrate in the single pipeline system has been controlled by an adjustable throttle valve at the entrance section of the pipeline and the flowrate has been measured by one of the digital turbine flowmeter installed after the throttle valve at the entrance section. The inlet pressure of the single pipeline system has been measured by one of the electronic pressure transducers attached between the throttle valve and the flowmeter at the entrance section of the pipeline system. The pipeline characteristics without leakage has been illustrated in Figure 9. The pipe line flowrate, $\mathrm{Q}_{\text {no-leak }}$, corresponding to the constant pressure head, $\mathrm{H}_{\text {no-leak }}=16.3 \mathrm{~m}$. has been determined from this measurement as shown in the figure.

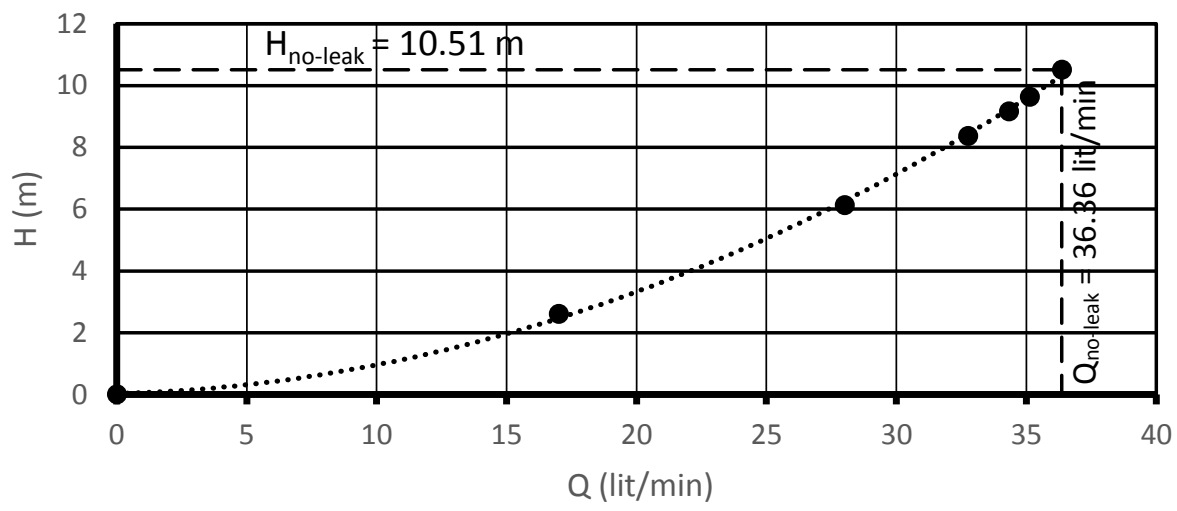

Fig. 9. Pipeline characteristics without leakage occurrence

\subsection{Effect of Leakage Occurrence on the Pressure Head and Flowrate at Pipeline Entrance}

Special connections with various openings, $d / D$ have been connected to the pipeline system at various distances, $\mathrm{x} / \mathrm{L}$, from the pipeline entrance of the test section in order to simulate the leakage in the pipeline system. The flowrate meters and the pressure transducers have been used to measure the inlet pressure head, h, at each flowrate. In Figure (14), the measured pressure head ratio $\left(\mathrm{H} / \mathrm{H}_{\text {no-leak }}\right)$ versus leakage location ratio $(\mathrm{x} / \mathrm{L})$ at various leakage opening (diameter ratios d/D) is presented while in in Figure (15) $\mathrm{Q}_{1} / \mathrm{Q}_{\text {no-leak }}$ at the entrance section of the pipeline versus leakage location, $x / L$ at various leakage opening ratios, $d / D$. In Figure (16) presents the measured $\mathrm{Q}_{2} / \mathrm{Q}_{\text {no-leak }}$ after leakage occurrence versus leakage location, $\mathrm{x} / \mathrm{L}$ at various leakage opening ratios, $\mathrm{d} / \mathrm{D}$.

\subsection{Verification of Theoretical Investigation of Pipeline System}

To verify the theoretical results, with the use of pipeline friction and local coefficients from the published charts [7] and [8], the experimentally measured values have been compared, as shown in Figure 12 for the static pressure heads $\left(\mathrm{H} / \mathrm{H}_{\text {no-leak }}\right)$ and in Figure 13 for the flowrates $\left(\mathrm{Q}_{\mathrm{i}} / \mathrm{Q}_{\text {no- }}\right.$ leak) versus the pipeline length $(\mathrm{x} / \mathrm{L})$, at various leakage openings, $\mathrm{d} / \mathrm{D}$. 


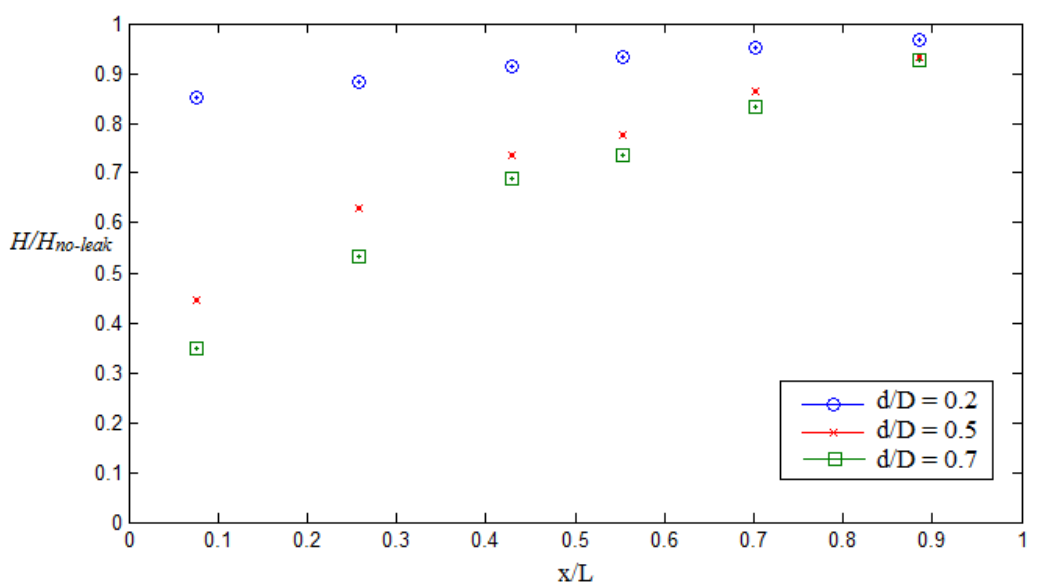

Fig. 10. Experimental measurements of static pressure head at pipeline entrance with leakage at various locations, $x / L$, from various leakage openings, $d / D$

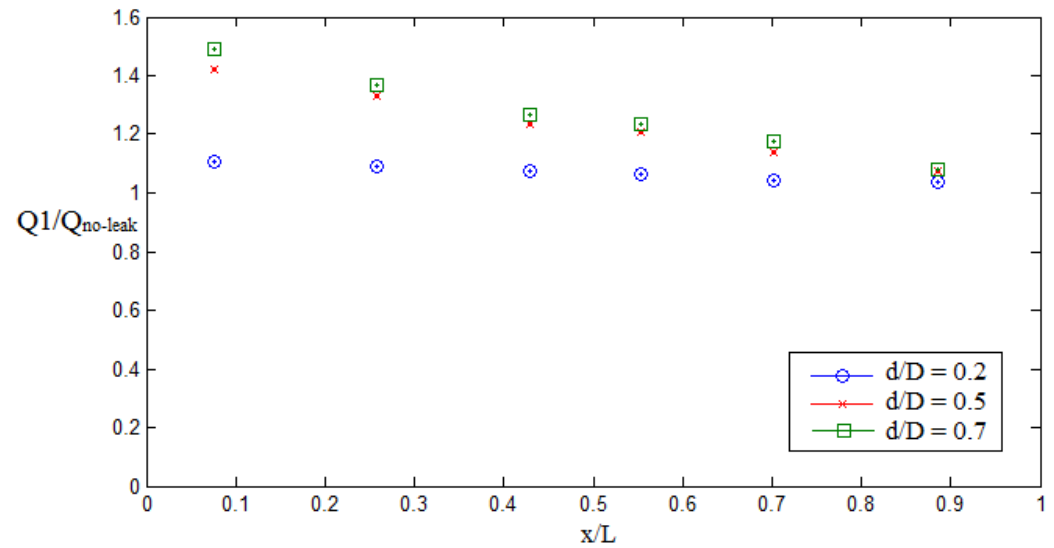

Fig. 11. Experimental measurements of flowrate upstream leakage exit at various locations, $x / L$, from various leakage openings, $d / D$

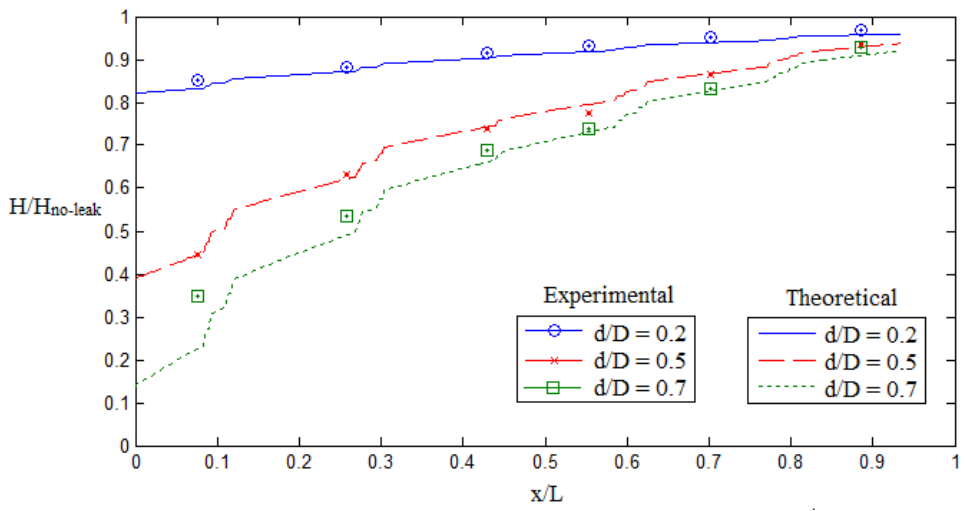

Fig. 12. Verification of theoretical results with experimental measurements of static pressure head at pipeline entrance with leakage at various locations, $x / L$, from various leakage openings, $d / D$ 


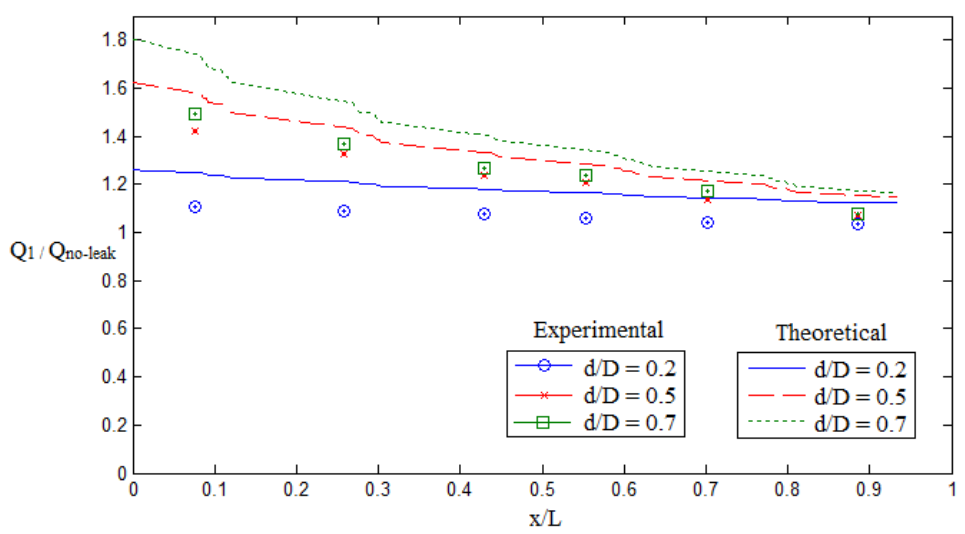

Fig. 13. Verification of theoretical results with experimental measurements of flowrate upstream leakage exit at various locations, $x / L$, from various leakage openings, $d / D$

An error analysis technique has been performed on both parameters, based on the mean square averaged error, and the errors were around $12 \%$ in the case of $\left(\mathrm{H} / \mathrm{H}_{\text {no-leak }}\right)$ values, and around $15 \%$ in the case of $\left(\mathrm{Q}_{\mathrm{i}} / \mathrm{Q}_{\text {no-leak }}\right)$ values. These results have been considered big errors and not accepted.

To minimize this big error, it has been decided to measure the pipe friction loss and all local losses directly on the test rig of the pipeline system instead of taking them from the published charts and tables. The measured friction head losses in a one meter polypropylene pipe of diameter one inch, shown in Figure 14, has been curve fitted and inserted into the theoretical program. The measured local losses coefficients in the exit section of the constant head tank, shown in Figure 15; in elbows, shown in Figure 16; and in the ball valve, shown in Figure 17, have been plotted and averaged $\left(\mathrm{K}_{\text {tank-exit }}=3, \mathrm{~K}_{\text {elbow }}=1.1\right.$, and $\left.\mathrm{K}_{\mathrm{valve}}=0.4\right)$. The local losses coefficients in the flow meter T-connection, shown in Figure 18, and in the branched pipes of leakage exits, shown in Figure 19, have been curve fitted and inserted into the theoretical program to enhance the theoretical results.

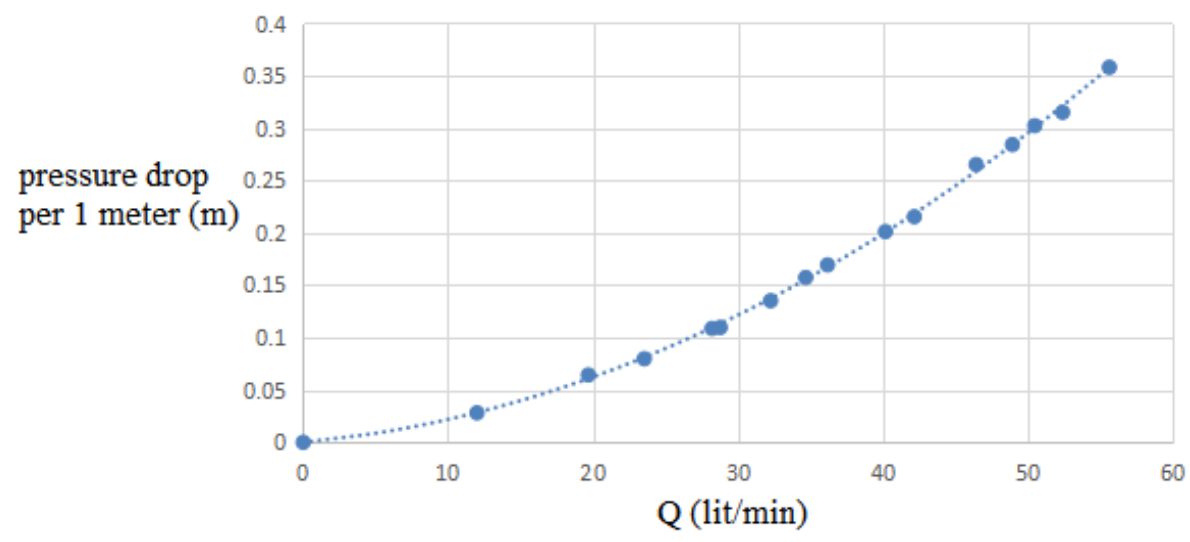

Fig. 14 Measured friction head losses in pipeline 


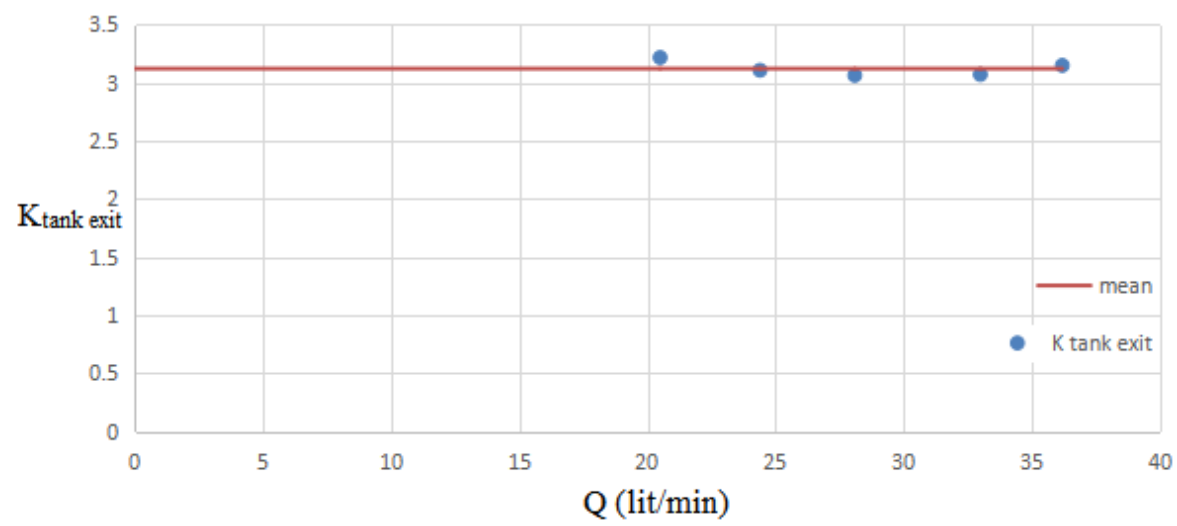

Fig. 15 Measured losses coefficient in tank exit

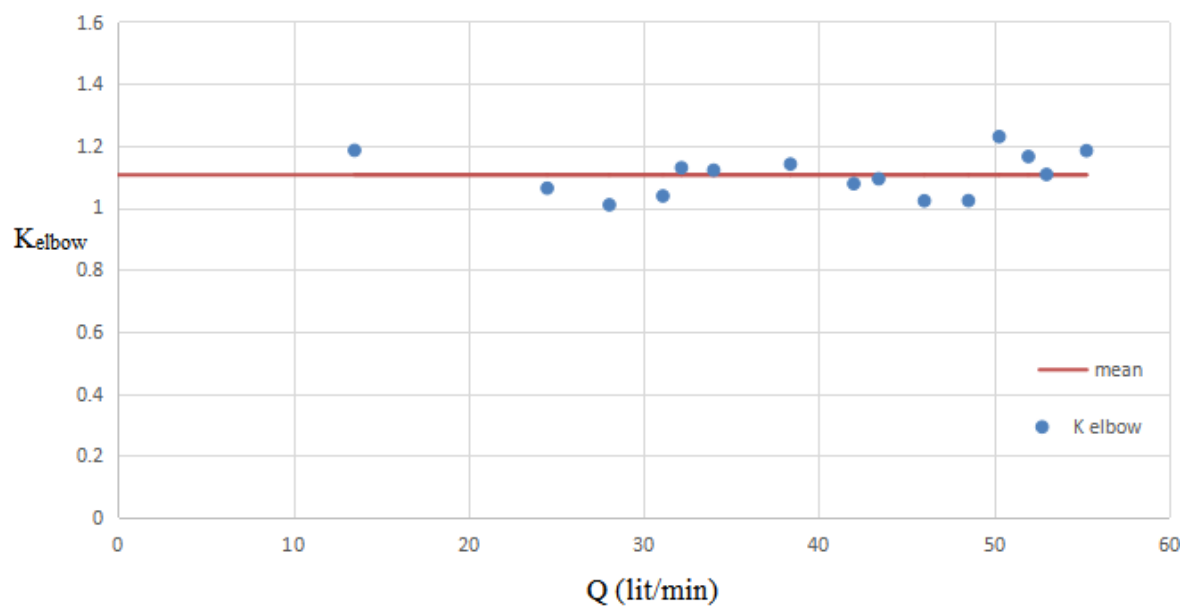

Fig. 16 Measured local losses coefficient in elbow

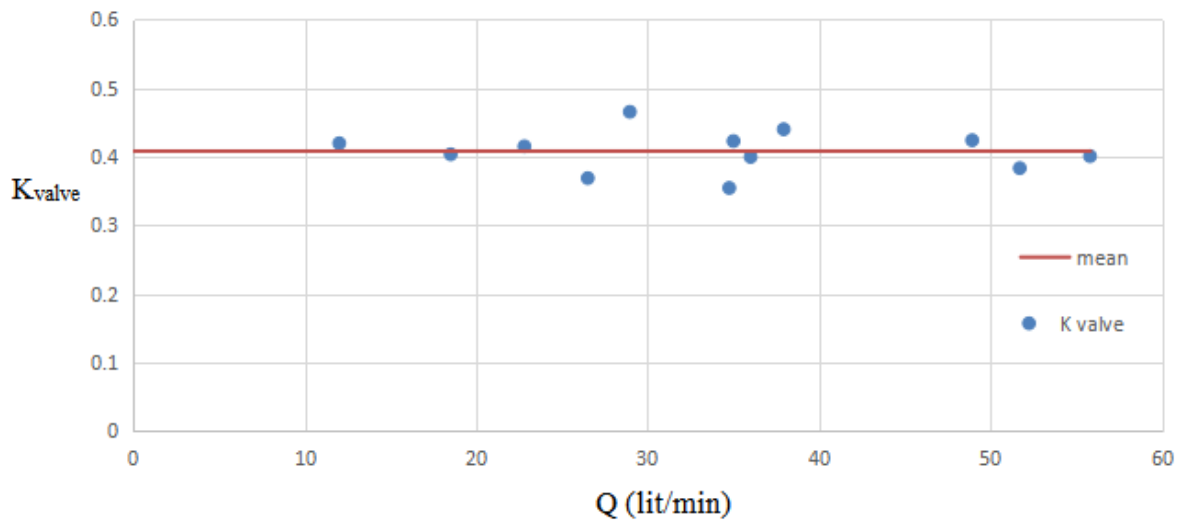

Fig. 17 Measured local losses coefficient in valve 


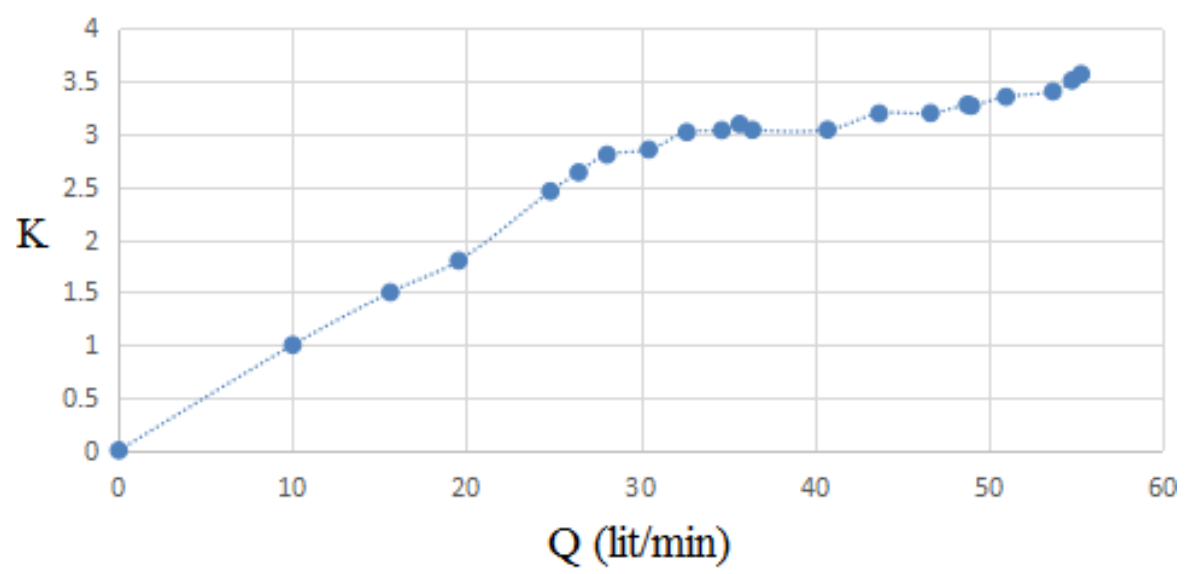

Fig. 18 Measured local losses coefficient in flowmeter T-connection

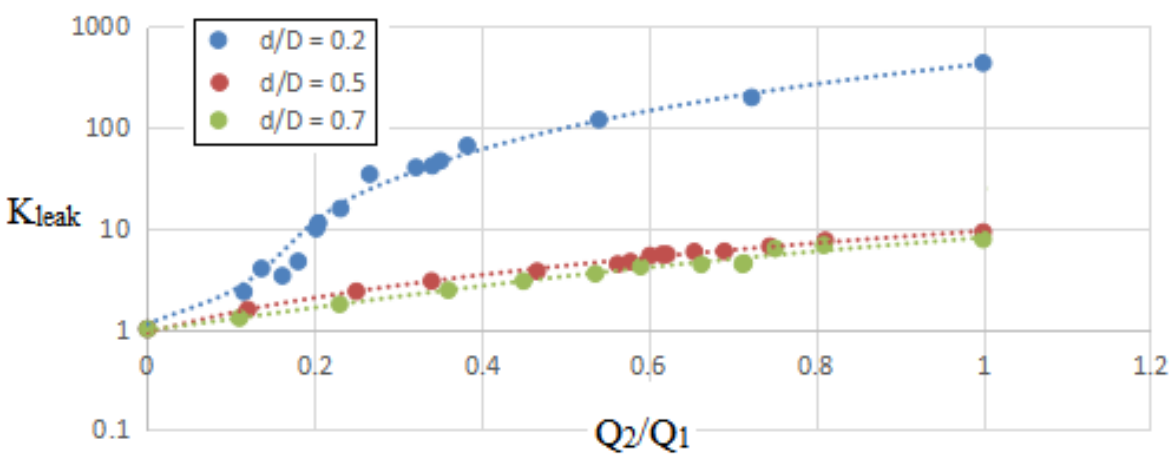

Fig. 19 Measured local losses coefficient in the leakage branched exits

The comparison between the experimentally measured values of local losses coefficients in the exit section of the constant head tank, elbow, and ball valve with their corresponding values in the published charts are presented in Table 1.

Table 1. Comparison between the experimentally measured values of the local loss coefficients and those calculated from the published charts and tables

\begin{tabular}{c|c|c|c}
\hline \hline Pipeline Fittings & $\begin{array}{c}\text { Exit section of } \\
\text { constant head tank }\end{array}$ & Elbow & Ball valve \\
\hline Published values of K [7] and [8] & 0.8 & 0.9 & 0.2 \\
\hline Experimental values of K & 3 & 1.1 & 0.4 \\
\hline
\end{tabular}

To check the validation of the simulation program after modification process by inserting the measured pipe friction and local losses, the static pressure heads $\left(\mathrm{H} / \mathrm{H}_{\text {no-leak }}\right)$, the flowrates (upstream $\mathrm{Q}_{1}$, at leakage exit $\mathrm{Q}_{2}$, and downstream $\mathrm{Q}_{3}$ ) versus leakage locations, $\mathrm{x} / \mathrm{L}$, along the pipeline at $\mathrm{d} / \mathrm{D}=0.5$, and flowrates $\left(\mathrm{Q}_{\mathrm{i}} / \mathrm{Q}_{\text {no-leak }}\right)$ versus the pipeline length $(\mathrm{x} / \mathrm{L})$, at various leakage openings, d/D, have been compared as shown in Figure 20, Figure 21, and Figure 22, respectively. The errors analysis has been performed, based on the mean square averaged error, and was around 3\% for both parameters which have been considered small errors and are accepted. 


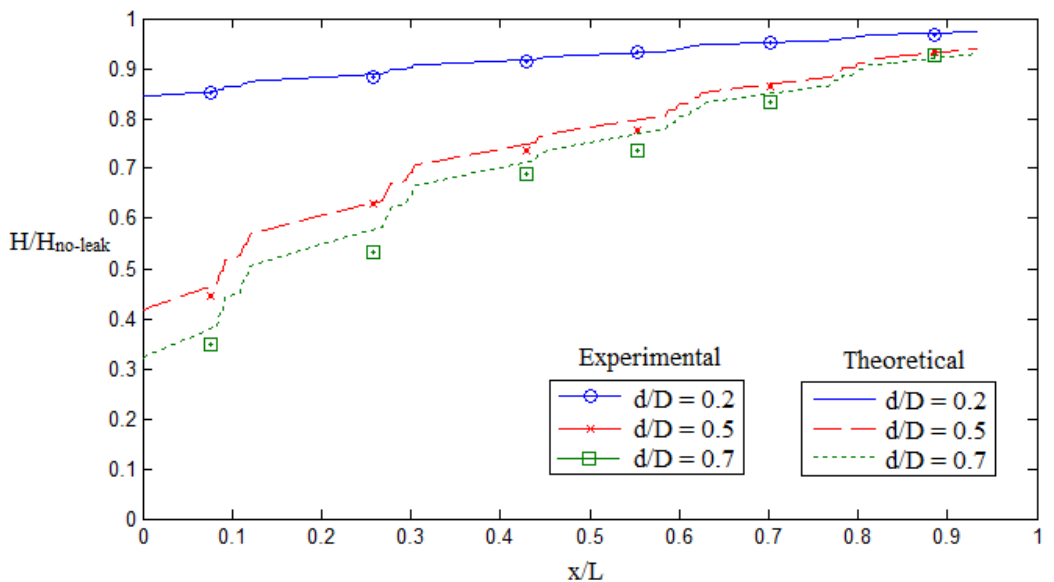

Fig. 20. Experimental verification of the modified theoretical results of pressure head at pipeline entrance with leakage at various locations, $x / L$, from various openings, $d / D$

Referring to the illustrated example of Figure 5, which presents the effect of leakage position on the behavior of the three discharges $\left(\mathrm{Q}_{1} / \mathrm{Q}_{\text {no-leak }}, \mathrm{Q}_{2} / \mathrm{Q}_{\text {no-leak}}, \mathrm{Q}_{3} / \mathrm{Q}_{\text {no-leak }}\right)$ downstream the pipeline system at various locations, $\boldsymbol{x} / \boldsymbol{L}$ in case of flow with leakage occurrence at exit diameter ratios $(d / D=0.5)$, Figure 21 demonstrates its verification when compared with the experimental measurements.

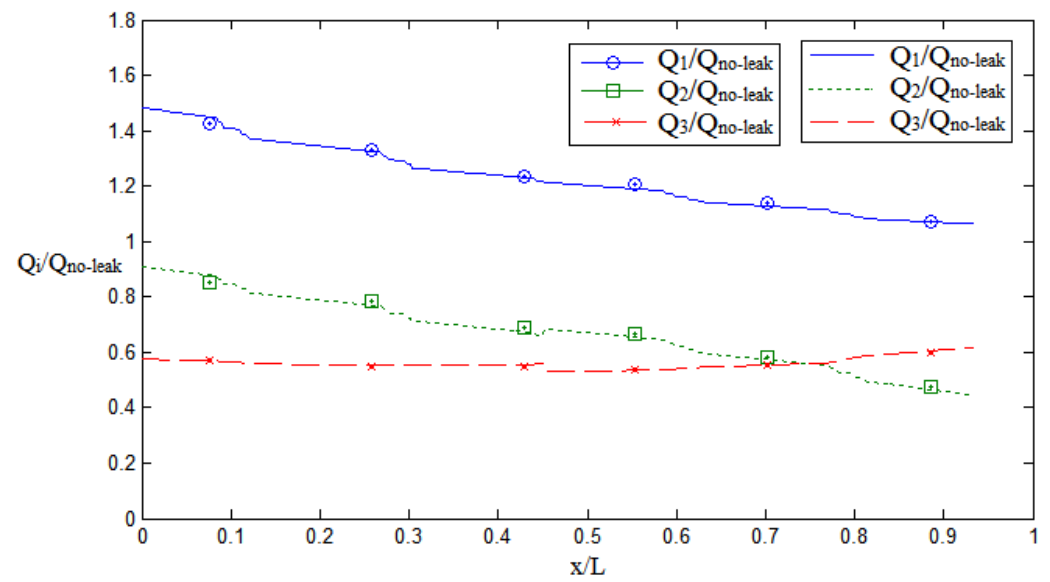

Fig. 21. Experimental verification of theoretical flowrates (upstream $Q_{1}$, at leakage exit $Q_{2}$, and downstream $Q_{3}$ ) versus leakage locations, $\mathrm{x} / \mathrm{L}$, along the pipeline at $\mathrm{d} / \mathrm{D}=\mathbf{0 . 5}$.

Now the theoretical and the experimental results are in good agreement, then the verified theoretical model could be used in prediction of the leakage location and flowrate (leakage opening) from the known values of static pressure head, $\mathrm{H}$, and upstream flowrate, $\mathrm{Q}$, at the pipeline entrance section, as have been noticed (concluded) in the present study of leak detection in pipeline systems. The details of this manipulation will be submitted in a future paper. 


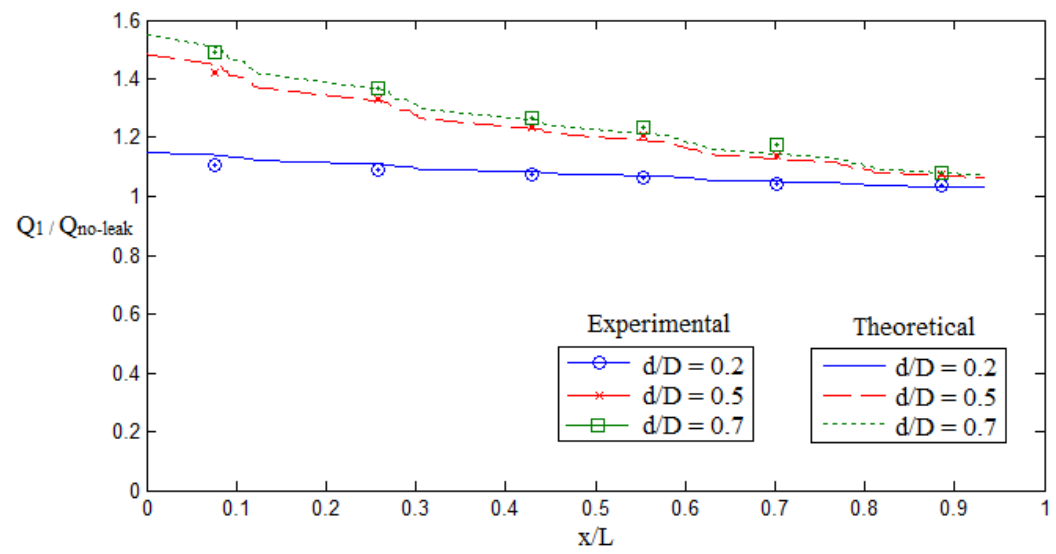

Fig. 22. Comparison of the modified theoretical results with experimental measurements of flowrate upstream leakage exit at various locations, $\mathrm{x} / \mathrm{L}$, from various leakage openings, $\mathrm{d} / \mathrm{D}$

\section{Conclusions}

Theoretical analysis and experimental measurements of the leakage detection in branched pipeline systems have been investigated in the present study. The theoretical analysis of a proposed pipeline system, supplied by water from a constant head tank, has been modeled by applying the flow governing equations using MATLAB. The pipeline characteristics (pressure head versus flowrate), without leakage occurrence, has been studied theoretically on the proposed model. The pipeline parameters (pressure head and flowrate) at pipeline entrance section, has been addressed for various leakage locations and at various leakage exit openings. The proposed pipeline system has been realized, as a test rig, in the fluid mechanics laboratory of the mechanical energy department in MTC. The fluid flow parameters (pressure and flowrate) have been measured experimentally in both cases of fluid flow without leakage occurrence and with leakage occurrence. The theoretical model has been validated from the experimental measurements after performing a comparison process. As a conclusion, the occurrence of leakage in pipeline system is pronounced by the change in the flow parameters (pressure and flowrate) at entrance section of the system. The location and the size of leakage opening (flowrate) are two main parameters affecting this observed change in flow parameters at pipeline entrance. So if the flow parameters (pressure and flowrate) at the entrance section of a pipeline system changed than the corresponding values in case of no leakage, it means that a leakage occurred. The correlation between the measured values of change in the flow parameters at pipeline entrance and the leakage (possible location and size of leakage opening) shall be manipulated and introduced in details in a future paper.

\section{References:}

[1] Z. Y. Wu, P. Sage, and D. Turtle, "Pressure-dependent leak detection model and its application to a district water system," Journal of Water Resources Planning and Management, vol. 136, pp. 116-128, 2009.

[2] A. Candelieri, D. Conti, and F. Archetti, "A graph based analysis of leak localization in urban water networks," Procedia Engineering, vol. 70, pp. 228-237, 2014.

[3] L. Á. Alarcón-Ramos and P. P. G. Pérez, "A Useful Application of a Simulator for Leak Events in Pipelines."

[4] W. Mpesha, S. L. Gassman, and M. H. Chaudhry, "Leak detection in pipes by frequency response method," Journal of Hydraulic Engineering, vol. 127, pp. 134-147, 2001 
[5] P. J. Lee, J. P. Vítkovský, M. F. Lambert, A. R. Simpson, and J. A. Liggett, "Frequency domain analysis for detecting pipeline leaks," Journal of Hydraulic Engineering, vol. 131, pp. 596-604, 2005.

[6] J. Gong, A. C. Zecchin, A. R. Simpson, and M. F. Lambert, "Frequency Response Diagram for Pipeline Leak Detection: Comparing the Odd and Even Harmonics," Journal of Water Resources Planning and Management, vol. 140, pp. 65-74, 2013.

[7] B. E. Larock, R. W. Jeppson, and G. Z. Watters, Hydraulics of pipeline systems: CRC press, 1999.

[8] Nakayama and R. Boucher, Introduction to fluid mechanics: Butterworth-Heinemann, 1998.

[9] H. M. Abozaid, A. S. Abou El-Azm Aly, and A. H. Lotfy, "Leak Detection in Pipeline Systems,", M.Sc. Thesis, Military Technical College, 2017, in preparation for discussion and publication.

[10] J. Zhang, "Designing a cost-effective and reliable pipeline leak-detection system," Pipes and Pipelines International, vol. 42, pp. 20-26, 1997. 